\title{
Cultivation of the Targeted Forest Plantations
}

\section{Ol'ga Kunickaya $^{1 *}$, Vadim Tanyukevich ${ }^{2}$, Daria Khmeleva ${ }^{2}$, Anastasia Kulik ${ }^{3}$, Elena Runova ${ }^{4}$, Vera Savchenkova $^{5}$, Anna Voronova ${ }^{6}$, Mikhail Lavrov $^{7}$}

${ }^{1}$ Yakut State Agricultural Academy, Yakutsk, Russian Federation

${ }^{2}$ Novocherkassk Reclamation Engineering Institute named after A. K. Kortunov - branch of Federal State Budgetary Educational Institution of higher professional education "Don State Agrarian University", Novocherkassk, Russian Federation

${ }^{3}$ Federal Scientific Centre of Agroecology, Complex Melioration and Protective Afforestation Russian Academy of Sciences, Volgograd, Russian Federation

${ }^{4}$ Bratsk State University, Bratsk, Russian Federation

${ }^{5}$ Mytischi Branch of Bauman Moscow State Technical University, Moscow, Russian Federation

${ }^{6}$ Petrozavodsk State University, Petrozavodsk, Russian Federation

${ }^{7}$ North-Eastern Federal University in Yakutsk, Yakutsk, Russian Federation

Received: 06/05/2020

Accepted: 17/09/2020

Published: 20/12/2020

\begin{abstract}
Targeted reforestation refers to ecosystems with natural and artificial energy reserves. Additional energy reserves are spent on growing and harvesting, various types of forest care, forest use, and delivery of products to consumers, including energy costs for all types of preparation. The wood to be harvested must be assessed on the energy consumption required for its production. The purpose of this work was to develop a comprehensive methodology to assess the energy effect, model the process of plantation operation considering the soil type, tree species, and technical parameters of operating machines. According to the estimation results of the trunk wood energy value, it has been established that depending on the growth rate and maturity level, the target plantations are divided into two types, which should be taken into account during planting and subsequent rotation. It is shown that with regard to the technological features of machine systems and the type of plantation, it is necessary to consider dimensional characteristics of the planting scheme and the technological cycle of exploiting the forest plantation. The results of mathematical modeling following the technological parameters of operating machines and all types of costs showed that the cost of the selected target species for reforestation can provide sufficient profit when optimizing the machine system operations. The principle of modular division of machines system on power, technological, and transport modules is offered, which vary in purpose, criteria of parameters optimization, and indicators of work. The obtained mathematical model and methodology of target planting optimization can be applied in forestry and agricultural complexes, as well as become the basis for further research in this direction.
\end{abstract}

Keywords: Targeted reforestation, Wood energy value, Productivity, Ecosystem management, Plantation preparation, Planting systems

\section{Introduction}

Targeted forest plantation is the result of artificial reforestation or forest-growing activities. Their creation is a very promising area of forest business and may have several objectives, for example, accelerated growth of target timber (forest plantations), creation of shelterbelts, as well as reducing greenhouse gas emissions through biophysical processes of carbon dioxide sequestration [1]. In all cases, forest plantations with specified operational and ecological properties are artificially created. In order to increase the efficiency of target forest plantations, the optimal choice of tree species to be planted is required, which will best meet the soil, climate, and operational objectives of their creation. An optimal choice of machine system and technological processes for site preparation, planting, and cultivation are needed as well [2].

The history of target forest plantations spans several decades, which allowed gaining significant forestry experience. At that time, countries such as Sweden, Finland, England, Serbia, Croatia, Hungary, the United States, Australia, and New Zealand began to pay considerable attention to this issue [3]. Energy plantations are those that have a harvest turnover of 2 to
15 years. The first target energy plantations for research purposes were planted in the USA, then in Germany and Yugoslavia, and after in Sweden [4]. In Sweden, for example, planting of fast-growing tree species for the pulp and paper industry began in the 1960s, and energy plantings of willow trees began in 1970 resulting in approximately $1 \%$ of country's annual timber harvest [5], mainly in southern and middle Sweden, where is the most favorable climate for this purpose. In Sweden, energy plantations with short cutting times are grown on an area of 1.200 ha for heat and electricity production. Whereas in 1984, about $14 \%$ of the energy produced in Sweden was derived from the dendro-mass, it was planned to increase this figure to $61 \%$ by 2015 [6]. The assessment and comparison results of the regional capacity in Northern Europe to cultivate fast-growing woody biomass showed that the potential for biomass productivity in fast-growing forest plantations is $\mathbf{5 8 . 5}$ million cubic meters per year [7]. Besides, according to these results, it has been established that the management strategy for the target forest plantations should be local rather than general. A review of the project results on fast-growing hybrid poplar and willow trees in various plantations of Canada also showed that these species are well adapted to climatic and soil changes and can be used to plant abandoned ores and old landfills to restore the 
fertility of these lands [8]. Similar results have been obtained for long-term monitoring and evaluation of shale quarries in Estonia [9]. Thus, the development and application of targeted reforestation strategies are relevant in terms of economic and environmental issues associated with increased carbon dioxide emissions into the atmosphere and intensive logging of natural forests.

Unfortunately, almost no co-educational forest plantations for growing the target timber were initiated on the territory of the Russian Federation until now. However, there is a great experience in creating forest shelterbelts for agricultural lands, especially in the regions of Krasnodar Krai, as well as creating fire spacings in the forests. For example, for improving fertile soils in the Kuban, large-scale activity has been carried out on protective forestation since 1949 [10], and as of 2013, the area of such plantations in the region was 122778.5 ha. Fire breaches are created by planting deciduous strips in coniferous forests, and after felling, the main part of the logging site begins to overgrow intensively with deciduous species of trees. Forest regeneration with hardwoods contributes to diminishing intensive burning and spread of the fire area in the initial stage of a forest fire [11]. Therefore, target forest plantations can be created both for obtaining target timber (fuel, balances, saw logs) and achieving environmental effects.

In terms of negative climate change, environmental pollution, increasing overcrowding, frequent droughts and crop failures, food shortages and clean drinking water shortages, and quickly evolving migration processes in this regard, the issue of sustainable and efficient land use is becoming increasingly important. Thus, more and more forest land is being used for agricultural crop planting after harvest. The principal difference between plantations of forest and traditional crops is the duration of the harvest, its size, as well as the fact that in forest plantations, a wide range of useful products, including fruits of forest plants and shrubs, mushrooms, etc. can be obtained for the turnover of felling [12]. It should be noted that conventional forest management significantly differs from agricultural production, which is mostly designed for the production of monocultures on certain areas, i.e. separate areas are allocated for animal husbandry, separate for annual and perennial monocultures, and the collection of products is usually performed at a certain time - the time of maturity of the harvest. In this case, the main difference of a natural forest is that a wide range of useful products can be obtained in one area at different times that provide multiple benefits for the livelihoods of local communities, as well as regional and national economies [13]. For example, a study on the economic benefits of target plantations and reforestation in China shows that it depends on such factors as population density, gross forest output, forest area, crop area, and area burned by forest fires. Positive correlations with forest plantations had areas planted with crops and population density depending on the region and the main activity performed in this region [14]. This information is also important when developing reforestation and target plantation projects. The willingness to adopt energy plantations is influenced, in particular, by farmers' and foresters' perceptions of the potential for continued profitability and flexibility in managing land resources. The widespread adoption of targeted plantations requires a range of socio-economic benefits, flexibility in land management, and sustainable land use [15].

Considering the productivity of ecological systems, the process of industrial production of agricultural products is cyclical and results in the appearance of a certain number of various products. In forest biogeocenosis, as in most other biological communities, the process of production is continuous in time, so the products should be attributed to the selected unit of time. A universal indicator of the qualitative forest management process that considers all the differences in natural and productive conditions of the forest area location can be determined based on the concepts of "ecological efficiency" and "energy quality".

\section{Problem Setting}

Exploitable forests, as well as agricultural land, are ecosystems with natural and artificial energy subsidies. As in agriculture, additional energy subsidies are spent on growing and harvesting various types of forest care, forest use, and delivery of products to consumers. It should also include energy costs for all types of preparation, especially transport routing. By analogy with productivity in agriculture, the harvested wood can be estimated by the energy required for its treatment. The purpose of this work was to develop a comprehensive methodology for assessing the energy effect, to model the process of plantation considering the soil type, tree species, and technical parameters of the operating machines. To achieve the set goal, it is necessary to perform the following tasks using mathematical modeling: (a) to develop a methodology for assessing the efficiency of forest management based on the energy effect; (b) to create a decision-making system that allows selecting units for exploiting forest tree plantations at maximum profit; and (c) to create a system for making optimal decisions on the choice of the target species, composition and the amount of fertilizer applied, as well as technology for the preparation of seeds or seedlings.

\section{Methods and materials}

To evaluate the energy consumption required for wood harvesting, the method of measuring the energy intensity of the logging operations developed by the scientific school "Advances in lumber industry and forestry" is used in this work [16].

The difference between the energy production costs (energy consumption for all phases of forest management) and energy value (energy intensity) of these products will show the absolute ecological effect of the process, i.e., its optimality. That is:

$W_{p r}-W_{\text {cons }}=W_{\text {eff }}$,

where $W_{p r}$ is the energy intensity of forest products; " $W_{\text {cons }}$ is costs required for all phases of receiving forest products; " $W_{\text {eff }}$ is the energy effect of the forest management process. Another requirement of the universal quality indicator for the forest management process can also be presented:

$\frac{W_{p r}}{W_{\text {cons }}} \Rightarrow \max$.

However, when assessing the quality of the forest management process by the proposed criterion, the indicators of energy intensity of forest products and the costs for all phases of obtaining forest products should be reduced to a single denominator based on the principle of improving the quality and decreasing the amount of energy in the chain of its transfer. To predict and analyze the dynamics of energy intensity required for trunk wood harvesting, the following comparative calculation was performed within the frameworks of methodology development for assessing the efficiency of forest management by the energy effect. The proposed comparison characterizes the energy intensity of coniferous and softwood plantations. It is known the relationship between the age of the secondary forest, average tree height, trunk diameter, and a number of trees per hectare (single-age undisturbed plantations) and the yield class. This information was used to obtain approximate dependencies 
for determining the wood stock per hectare of forest-covered areas depending on the age of the timber stand. Afterward, using the recommendations for determining the wood density in the air-dry state, the obtained dependencies were converted into the air-dry wood mass distributed on 1 hectare of forestcovered area. Thus, the formula for determining the energy value of trunk wood per 1 ha of the area obtained using the data on the ratio between the calorific value of the wood mass unit and its moisture content (depending on the species) is as follows $(\mathrm{GJ} / \mathrm{ha})$ :

$W_{p r}(t)=A_{0}\left\{\frac{a_{0} a_{1} a_{2} \exp \left[\frac{\left[a_{0} a_{1} a_{3}+a_{2}\right) \cdot t}{a_{1}}\right]-a_{0} a_{1} a_{2}}{a_{0} a_{1} a_{3}+a_{2} \exp \left[\frac{\left(a_{0} a_{1} a_{3}+a_{2}\right) \cdot t}{a_{1}}-1\right]}\right\}^{A_{1}}$

Afterward, the empirically determined coefficients included in the formula (3) for different species were calculated (Table 1). For growing the specified timber yards, e.g., for use as fuel, such tree planting parameters as row spacing and tree spacing are selected depending on the technical parameters of the harvesting machine complex and the type of plantation. The distance between rows of trees is $2.5-3 \mathrm{~m}$ due to the use of specific harvesting equipment. Consequently, from 5000 to 10000 seedlings can be planted on 1 hectare, and this number varies depending on the quality of soil, growing time, and an available fleet of harvesting machines. For example, for energy plantations from poplar clones, the scheme of $3.0 \times 0.5 \mathrm{~m}$ is employed. At that, the distance between the tree rows of $3 \mathrm{~m}$ is chosen based on what is the most suitable in terms of the parameters of applied machines for the plantations care and machines for the chips preparation, and the distance of $0.5 \mathrm{~m}$ between the trees is most suitable for maximum yield of phytomass and is optimal for manual care of trees. Germinated and not germinated seeds, cuttings, seedlings, and nurslings can be used as planting material. The cuttings are carved out of quality branches and usually have a length of $20 \mathrm{~cm}$, while for certain species, this length reaches 1-3 $\mathrm{m}$. The cuttings are soaked in water 24 hours before planting. Planting of cuttings can be performed either by landers or manually.

In both cases, compaction of the soil around the cuttings is mandatory as a prerequisite for the formation of a quality root system. For cuttings, the planting is possible only in spring, while planting from germinated cuttings can be carried out both in early spring and autumn. Based on the scientific and design developments of the Hungarian specialists, a scope of special forestry machinery for the energy plantation of planting cuttings was created [4]. For example, a single or multi-row cuttings planting machine with a sliding plowshare without a feed gearbox (Fig. 1), twinned (one or 2-3 pairs) cuttings planting machine with a sliding plowshare without a feed gearbox (Fig. 2 ), or a two-row cuttings planting machine with a semi-automatic push-up feeding system (Fig. 3), etc.

Table 1: Regression model factors (3) for determining the energy intensity of forest products (trunk wood) as a function of timber stand age and yield class

\begin{tabular}{|c|c|c|c|c|c|c|c|}
\hline \multirow{2}{*}{ Species } & \multirow{2}{*}{ Yield class } & \multicolumn{6}{|c|}{ Factor } \\
\hline & & $a_{0}$ & $a_{1}$ & $a_{2}$ & $a_{3}$ & $A_{0}$ & $A_{1}$ \\
\hline \multirow{9}{*}{$\stackrel{\Xi}{\Xi}$} & I (Ic) & 0.9 & 45.268 & 0.6883 & 0.0225 & \multirow{9}{*}{0.5282} & \multirow{9}{*}{1.1244} \\
\hline & II (Ib) & 0.9 & 40.75 & 0.596 & 0.0239 & & \\
\hline & III (Ia) & 0.9 & 35.723 & 0.5104 & 0.0249 & & \\
\hline & IV (I) & 0.9 & 31.966 & 0.4303 & 0.0229 & & \\
\hline & $\mathrm{V}$ (II) & 0.9 & 28.536 & 0.348 & 0.0201 & & \\
\hline & VI (III) & 0.9 & 24.057 & 0.2615 & 0.0209 & & \\
\hline & VII (IV) & 0.9 & 19.948 & 0.186 & 0.022 & & \\
\hline & VIII (V) & 0.9 & 15.141 & 0.1258 & 0.0273 & & \\
\hline & IX (Va) & 0.9 & 11.143 & 0.0772 & 0.0337 & & \\
\hline \multirow{9}{*}{ 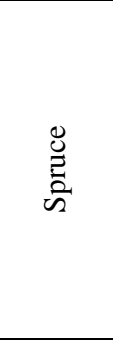 } & I (Ic) & 0,9 & 47.588 & 0.4045 & 0.0322 & \multirow{9}{*}{0.1692} & \multirow{9}{*}{1.4654} \\
\hline & II (Ib) & 0,9 & 42.902 & 0.3538 & 0.0322 & & \\
\hline & III (Ia) & 0,9 & 38.279 & 0.2999 & 0.0326 & & \\
\hline & IV (I) & 0,9 & 33.741 & 0.2375 & 0.0334 & & \\
\hline & V (II) & 0,9 & 29.036 & 0.1708 & 0.036 & & \\
\hline & VI (III) & 0,9 & 24.32 & 0.1196 & 0.038 & & \\
\hline & VII (IV) & 0,9 & 19.545 & 0.0802 & 0.0398 & & \\
\hline & VIII (V) & 0.9 & 15.617 & 0.0511 & 0.0438 & & \\
\hline & IX (Va) & 0.9 & 12.375 & 0.0353 & 0.0419 & & \\
\hline \multirow{7}{*}{ 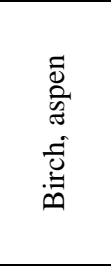 } & II (Ib) & 0.95 & 37.24 & 1.1125 & 0.0146 & \multirow{7}{*}{0.1371} & \multirow{7}{*}{1.5369} \\
\hline & III (Ia) & 0.95 & 33.785 & 0.8575 & 0.0108 & & \\
\hline & IV (I) & 0.95 & 29.805 & 0.6116 & 0.0146 & & \\
\hline & V (II) & 0.95 & 26.68 & 0.4244 & 0.017 & & \\
\hline & VI (III) & 0.95 & 21.172 & 0.2726 & 0.0268 & & \\
\hline & VII (IV) & 0.95 & 16.688 & 0.1639 & 0.0343 & & \\
\hline & VIII (V) & 0.95 & 13.526 & 0.0942 & 0.0399 & & \\
\hline \multirow{6}{*}{$\stackrel{3}{\stackrel{3}{\equiv}}$} & I (Ic) & 0.95 & 40.485 & 2.4002 & -0.015 & \multirow{6}{*}{0.0884} & \multirow{6}{*}{1.7243} \\
\hline & II (Ib) & 0.95 & 37.197 & 1.6509 & -0.007 & & \\
\hline & III (Ia) & 0.95 & 33.071 & 1.0526 & 0.0106 & & \\
\hline & IV (I) & 0.95 & 28.012 & 0.6504 & 0.027 & & \\
\hline & V (II) & 0.95 & 23.763 & 0.4005 & 0.0355 & & \\
\hline & VI (III) & 0.95 & 19.513 & 0.2451 & 0.0372 & & \\
\hline
\end{tabular}




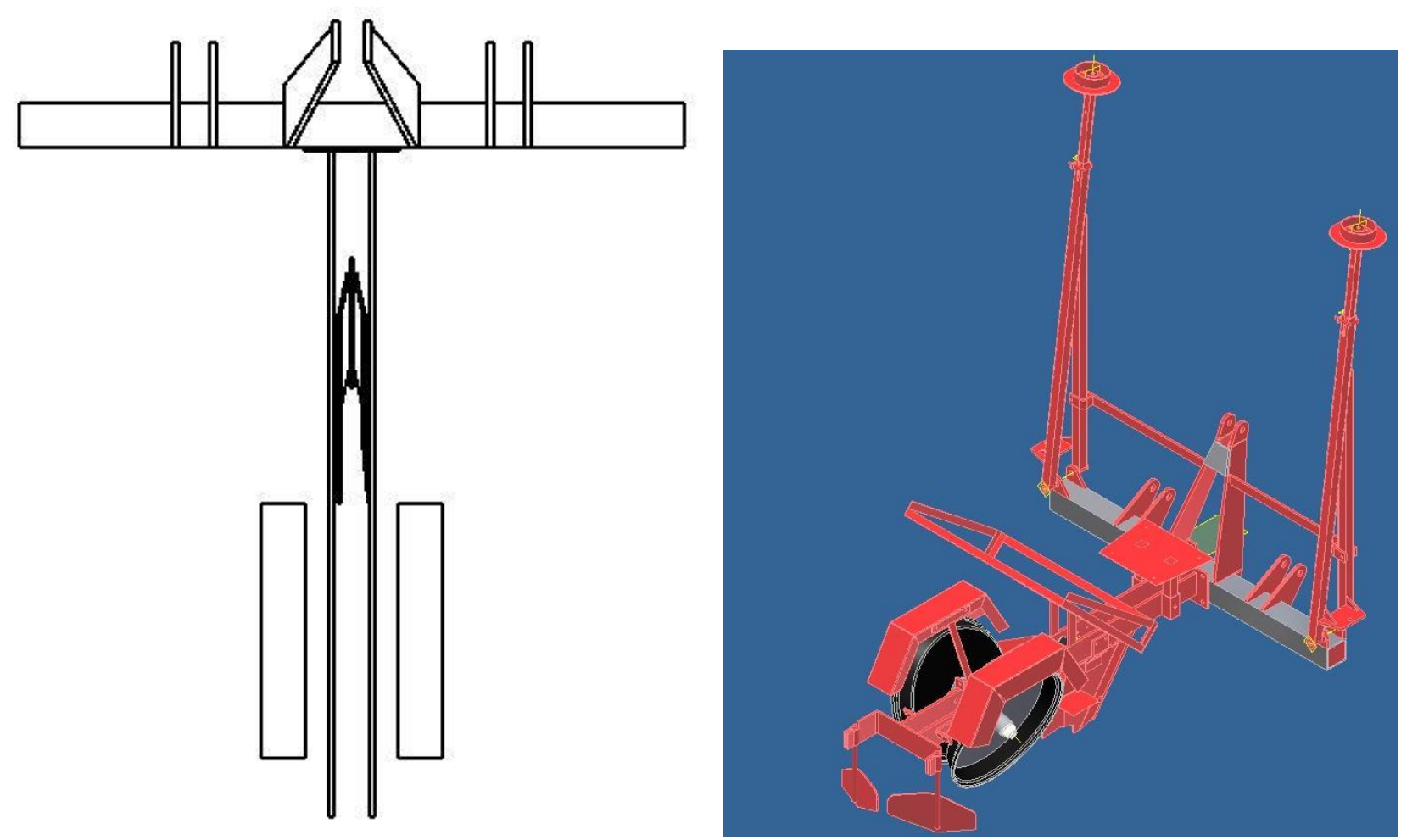

Figure 1: Single-row planter for cuttings planting
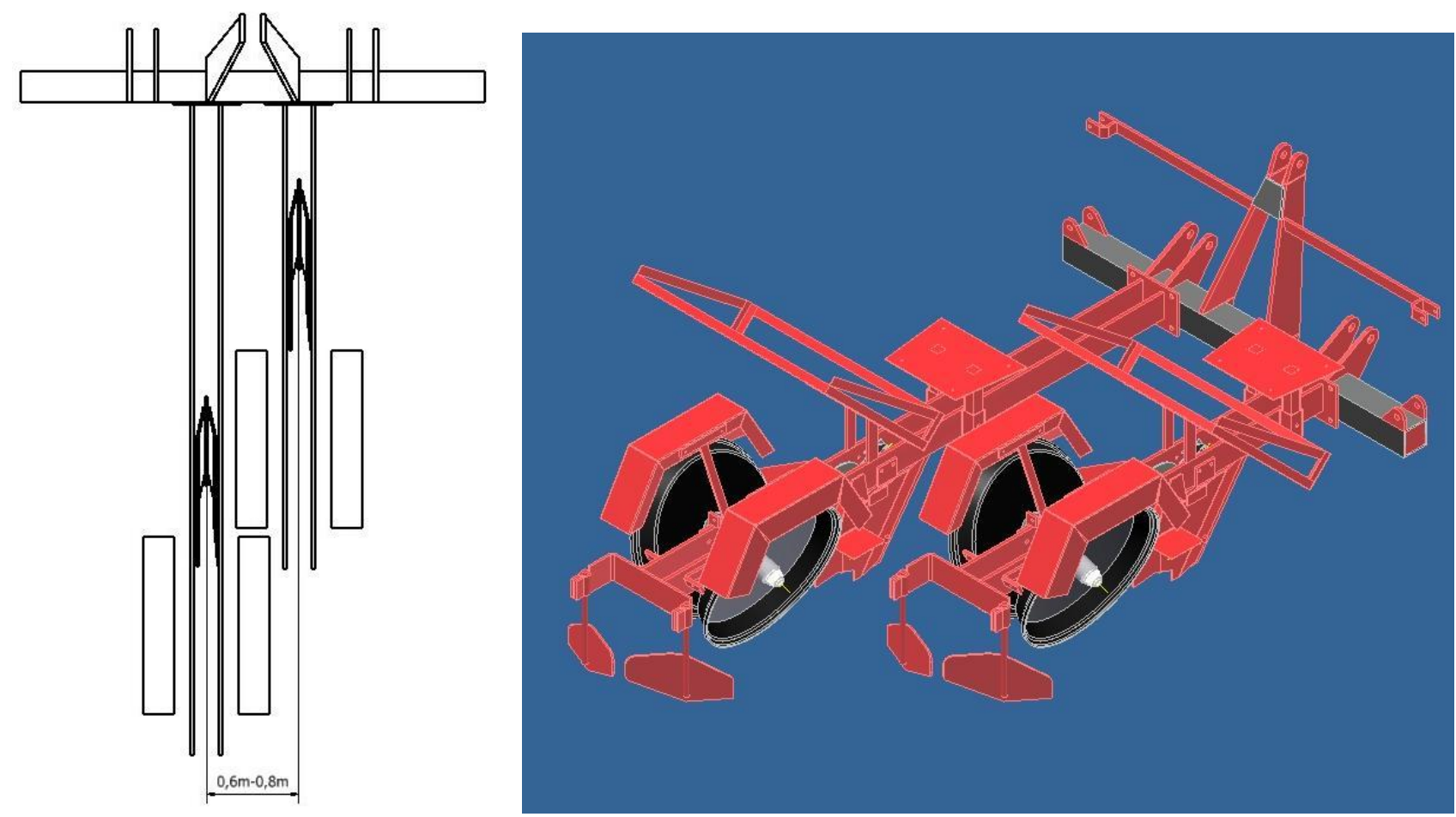

Figure 2: Planter for cuttings planting in one twinned row 


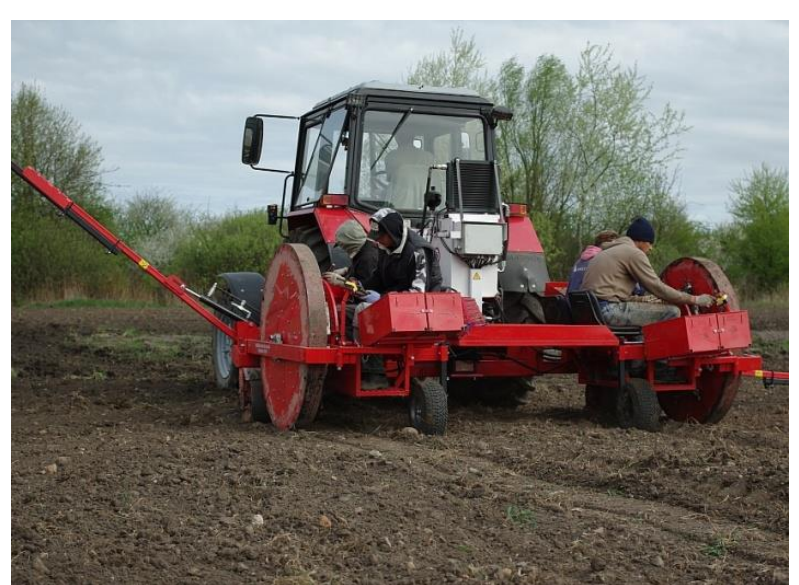

Figure 3: Planter (two-row) with semi-automatic push-up feeding system for energy plantations

The methods of mathematical modeling and optimization are proposed to solve the set tasks.

\section{Results and discussion}

\section{Assessing the accumulation of wood energy value}

The graphs in Fig. 4 are constructed according to formula (3) with the application of empirically determined factors and show the dynamics of accumulating energy value of trunk wood on 1-hectare area (by the example of II yield class for aspen and birch and I yield class for the other species considered). Thus, by the maturity age of deciduous tree species (60 years), they accumulate more energy than conifers, whose maturity age is much higher, especially for willow. Afterward, the energy reserves of the soft-wood species decrease due to overmaturity and increasing tree mortality. The reforestation of coniferous stands after the final felling requires significant energy costs for the soil preparation and production of the planting material in case of artificial reforestation, while softwood species have twice as smaller felling turnover. Therefore, in terms of ecological (energy) efficiency of forest management, it is preferable to make a crop rotation, alternating in time coniferous trees with softwood ones. Target energy plantations are divided into two main types. The first type is energy plantations of tree species on a coppice basis, the main difference of which is planting a significant number of seedlings (12-15 thousand pcs./ha). At that, the maximum age of cutting is $2-5$ years. When using this type, the main purpose of the plantation is to produce a phytomass of wood in the form of fuel chips. The data on the mass accumulation of energy wood in a completely dry state, or atrophies for three tree species, are given in Table 1 and illustrated in Figure 5. The second type is the energy tree plantations of trunk origin, i.e., with planting trees at each rotation. In this case, the fast-growing tree species are planted, which most correspond to the available soil quality in the highest possible quantity. Usually, 8-10 thousand pieces per hectare with the maximum felling turnover of $8-15$ years is planted. Elaborating such types of plantations results in obtaining fuel chips and technological wood. Depending on the age of the harvesting (felling turnover), the target energy forest plantations are classified into the following groups: (a) short (cutting turnover of up to 5 years); (b) medium (cutting turnover of 5-10 or $10-15$ years); and (c) long (cutting turnover of $10-20$ or $15-30$ years).

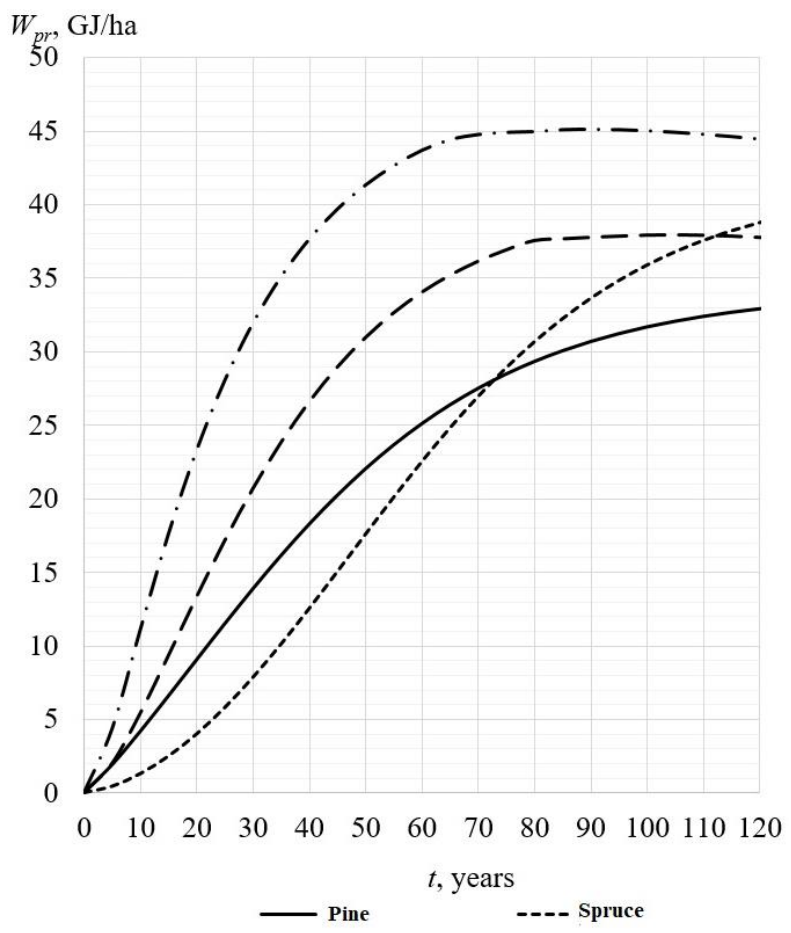

Figure 4: Accumulating the energy value of trunk wood per 1-hectare area (on the example of II yield class for aspen and birch and I yield class for other species considered)

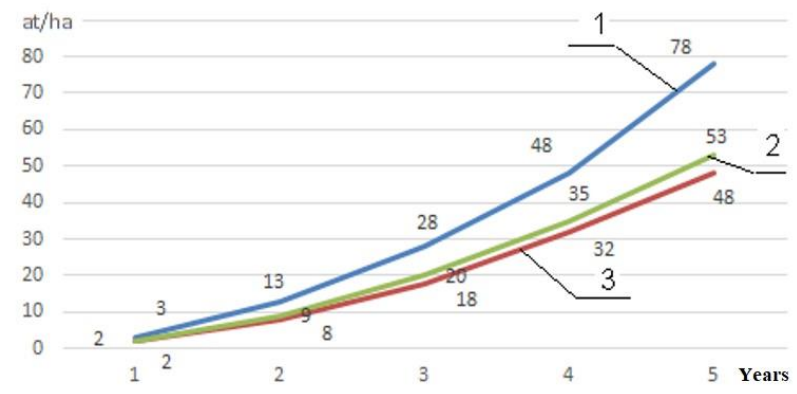

Figure 5: Mass accumulation of energy wood in absolutely dry condition: 1) poplar; 2) willow; 3) acacia

Table 2: Mass accumulation of energy wood in absolutely dry condition

\begin{tabular}{|c|c|c|c|c|c|c|}
\hline \multirow[b]{2}{*}{ Age } & \multicolumn{2}{|l|}{ Poplar } & \multicolumn{2}{|l|}{ Acacia } & \multicolumn{2}{|l|}{ Willow } \\
\hline & $\begin{array}{l}\text { Optimal location } \\
\text { of growing }\end{array}$ & $\begin{array}{l}\text { Accumulated } \\
\text { yields }\end{array}$ & $\begin{array}{l}\text { Optimal location } \\
\text { of growing }\end{array}$ & $\begin{array}{l}\text { Accumulated } \\
\text { yields }\end{array}$ & $\begin{array}{l}\text { Optimal location } \\
\text { of growing }\end{array}$ & $\begin{array}{l}\text { Accumulated } \\
\text { yields }\end{array}$ \\
\hline years & at/ ha/years & at $/ \mathrm{ha}$ & at/ha/years & at/ha & at/ ha/years & at/ha \\
\hline 1 & 3 & 3 & 2 & 2 & 2 & 2 \\
\hline 2 & 10 & 13 & 6 & 8 & 7 & 9 \\
\hline 3 & 15 & 28 & 10 & 18 & 11 & 20 \\
\hline 4 & 20 & 48 & 14 & 32 & 15 & 35 \\
\hline 5 & 30 & 78 & 16 & 48 & 18 & 53 \\
\hline
\end{tabular}




\section{Assessing technological requirements for exploitation of tar- get plantations}

For planting and maintaining energy plantations according to the technical characteristics of the planting machines, the following requirements must be considered. The dimensional characteristics of the single-row cuttings plantation scheme are as follows (Fig. 6): row spacing is $1.5-2.8 \mathrm{~m}$ and the spacing of cuttings is $0.4-1.0 \mathrm{~m}$. Dimensional characteristics of the twinrow cuttings planting scheme (Fig. 7) are as follows: row spacing is $2.0-2.8 \mathrm{~m}$, the spacing of cuttings is $0.4-1.0 \mathrm{~m}$, and the twin-row spacing is $0.6-0.8 \mathrm{~m}$.

To meet these conditions in Hungary, a team of employees [4] has developed the BGT-ETG-E machine system, which can perform all the necessary operations. These machines and equipment allow planting with different spacing between rows of trees. Also, this system includes soil tillage equipment, seed drills, planting machines, and care machines. At target reforestation, the careful choice of the target species, cutting turnover, composition and quantity of fertilizers applied, as well as technology for preparing seeds or seedlings is required. The technological cycle of exploiting the forest plantation can be divided into stages: (a) preparing the site for planting (sowing) of wood species. This stage involves mainly the preparation of soil, in some cases, preliminary clearance of the site from stumps. The technological equipment used in this process includes pullers, mulchers, plows, harrows, harrows, rippers, soil-cutters, etc. (b) Planting (sowing) of woody crops depending on the selected species for target forestry. At this stage, planting machines, seeders, rollers, etc. are used. (c) Planting care, which consists in creating optimal conditions for the growth of the target tree species. At this stage, cultivators, machines for additional fertilization, machines for controlling tree species pests, e.g., sprayers, hand pruners, etc. are used; (d) Harvesting the grown crop and logging, when the specified turnover of felling is achieved. At this stage, different technological equipment is used, depending on the purpose and size of the grown wood. When growing structural or balance wood, a system of machines for logging operations consists of harvester and forwarder, or felling and packaging machines, as well as skidder and processor. For small areas and reserves, the chainsaws and harvester, or combination of chainsaws, harvester and processor in the upper stage are applied. For energy wood (thin wood, respectively), the felling and chopping machine, or mulch and skidder are used. (E) The last stage of the technological chain is clearing of the plantation from the vegetation remainders, collection of cutting residues, dressing or shredding of stumps, roots, and re-cultivation of the land for transfer to other uses, or the return to the first stage, i.e., preparation of the site for a new cycle of target cultivation of forest plantations.

Each step requires a set of operations to be performed. Operations can be performed by various units at different costs, performance, energy efficiency, and technical availability. An assembly will be considered as a set of machines and equipment designed to perform a specific operation. Depending on the soil type, contamination, and target species, a set of operations is assigned to each stage. A set of possible machine units and equipment is assigned for each operation.

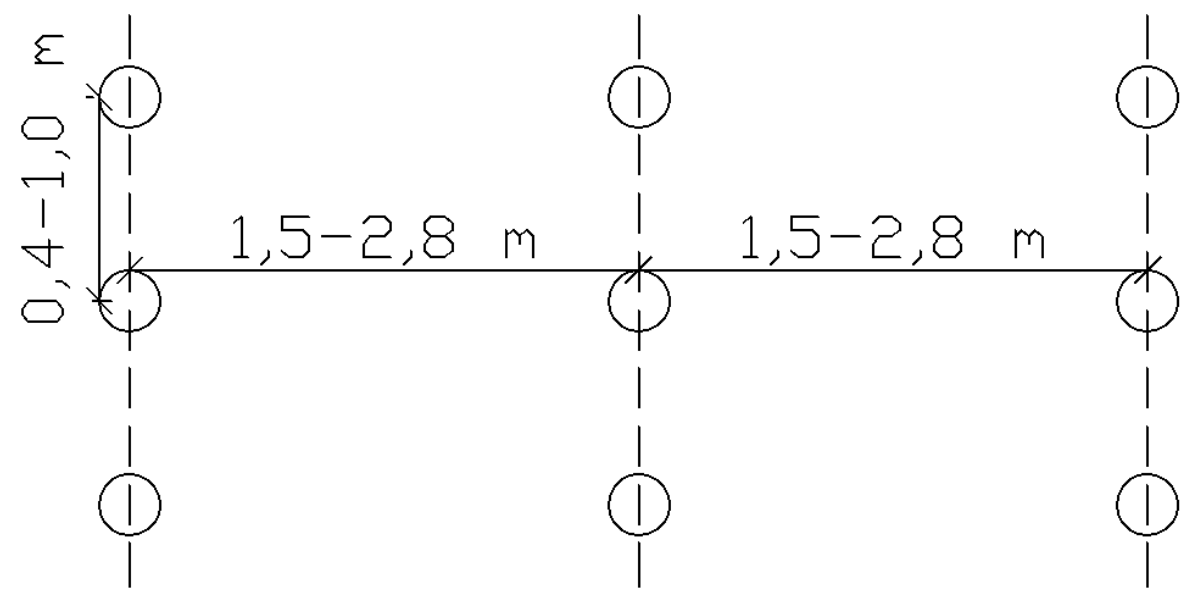

Figure 6: The scheme of planting is one-row

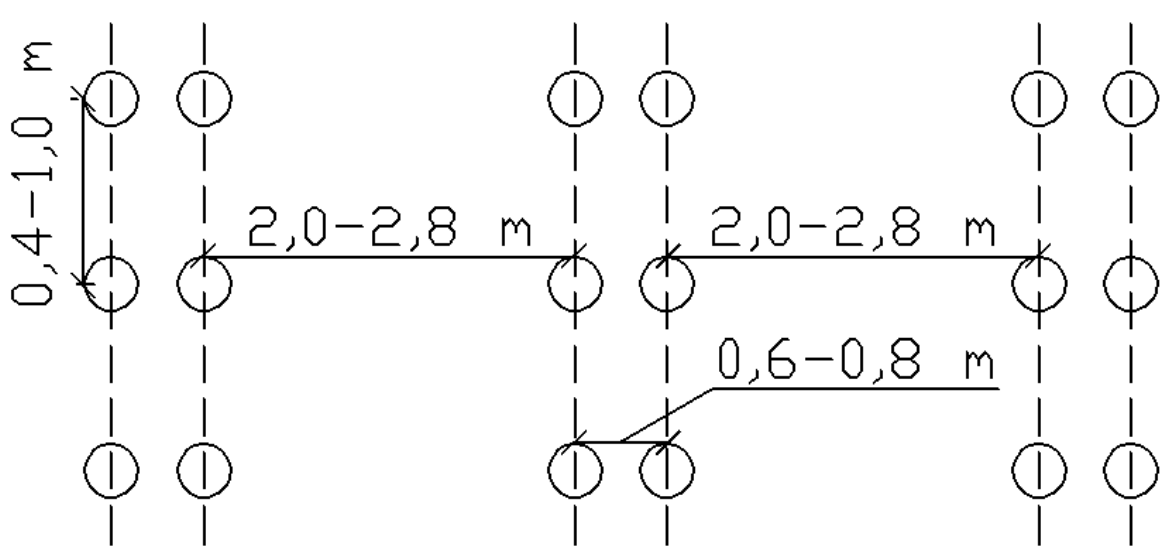

Figure 7: The twin-row planting scheme 


\section{Model for optimized selection of technological parameters}

The mathematical model describing the rationale of technologies and the choice of parameters for the machine's operation at timber enterprises is based on the following assumptions. Some works are seasonal, e.g., planting. The equipment for these works is idle most of the time. Other works are dependent on weather conditions and may continue most of the year. Accordingly, there can be several options for the selection and operation of machines and equipment. It should be noted that one operation can be performed by different units and one machine or equipment unit can be used to perform different operations. For example, it is possible to install different types of attachments on a tractor: plows, pullers, stump cutters, sprayers, manipulators, mulching machines, etc. Consequently, different operations can be performed with one machine [17]. The following designations are to be presented:

$n$ is number of stages; $N$ is indices multitude of technological operations; $N_{t}$ is indices multitude of technological operations for the stage $t, N_{t} \subset N, t=1, \ldots, n ; M$ is indices multitude of machine's assembly; $Q$ is indices multitude of machine and equipment units; $R$ is relation that defines the connection between technological operations and the units performing them, $R \subset M \times N ; A$ is relationship matrix $R$, which consists of elements $a_{i j}, i \in M, j \in N$, where $a_{i j}=1$, if operation $j$ can be performed by the equipment unit $i$ and $a_{i j} i s 0$, otherwise; $B$ is matrix, that consists of elements $b_{q i}, q \in Q, i \in M$, where $b_{q i}=1$, if the equipment unit $i$ includes a machine or a facility $q$ and $b_{q i}=0$, otherwise. Exogenous variables (input parameters): $S$ is square of the area (ha); $w_{i j}$ is unit efficiency $i \in M$ at performing technological operation (ha/h) $j \in N ; T_{t}$ is critical time for one stage $t, t=1, \ldots, n ; c_{q}$ is cost of one equipment unit $q \in Q$. Endogenous variables (unknown models): $x_{q}$ is number of units of type $i$ used in technological cycle $q \in Q ; y_{i j}$ $i$ is binary variable equal to 1 , if the equipment unit $i$ is used for technological operation $j \in N$ and 0 - otherwise, $i \in M ; z_{i j}$ is number of units of type $i$ used for technological operations $j \in$ $N, i \in M$. Target function is minimal costs for equipment and machines:

$\sum_{q \in Q} c_{q} x_{q} \rightarrow \min$,

The scope of work on every stage should be performed completely:

$\sum_{i \in M} w_{i j} z_{i j} T_{t} \geq S, j \in N_{t}, \quad t=1, \ldots, n$,

For every operation, one type of equipment should be chosen:

$\sum_{i \in M} y_{i j}=1, j \in N$,

All operations should be performed on specified equipment:

$0 \leq y_{i j} \leq a_{i j}, \quad i \in M, j \in N$

The number of equipment used is integer:

$y_{i j}$-integer, $i \in M, j \in N$,

Units are complemented only for planned operations:

$0 \leq z_{i j} \leq D y_{i j}, \quad i \in M, j \in N$, where $D$ is quite high constant (a number, which is higher than any other possible value of the variable $z_{i j}$ );

$x_{q} \geq b_{q i} z_{i j}, \quad q \in Q, i \in M, j \in N$.

In such a mathematical model, the target species for plantation are assumed as selected, and the amount of wood grown on the site is known accordingly. The cost of providing a sufficient percentage of profit should be determined as well. Otherwise, a change is required, e.g., in the target species.

\section{Principle of modular machine's system construction}

Machines and technological equipment are used periodically and consistently when creating target forest plantations. This, in turn, assumes that the system of machines in the process of target reforestation is optimally created according to the modular principle similar to the layout of machinery systems of agricultural production. It should be noted that different time intervals are allocated for different types of work in the same area, i.e., if to bring the productivity of all operations to a single denominator, hectares of the target forest area, their productivity can be different. The principle of modular construction of the machine system consists of the division into three types of modules: energy, technological, and transport. Energy modules are tractors of different traction class, providing with energy the performance of workers, mixed, and transport operations. For the latter, the issue should be considered only within the area allocated for the target forest plantation with a loading platform (upper storage) at it. When creating and operating forest plantations, transport modules should carry out delivery of seeds or seedlings to the place of sowing (planting), as well as the delivery and application of fertilizers, pesticides, etc., and skidding of harvested wood biomass and cuttings residue. Technological modules, in their turn, provide soil preparation, seeds or seedlings embedding, loosening, as well as other necessary forestry operations like cutting and treatment of cultivated woody and shrub vegetation. Based on the different purposes of the modules, the criteria for optimizing their parameters and performance will also vary.

For the overall machine's system layout, it is highly desirable to have as few modules as possible, at least in terms of reducing the required capital investment. It is well known that one of the criteria for the optimal choice of machine system is that the most expensive machine, or equipment, would have the maximum load. That is, any equipment must pay off itself and still bring profit during the time of resource development. The criterion of the energy module optimality is the correspondence of power unit (engine) capacity and concentration of energy on the needs of technological and transport modules working with it. If a large and powerful tractor will be equipped with a small trolley to transport the necessary cargo, or cultivator with a small grip, the energy efficiency of such a system will be extremely low, if not negative. Alternatively, by using a tractor with a small traction class and an engine power greater than required to perform the technological or transport operation at a given speed, the operation will either not be completed at all interrupting, thus, the entire process chain, or the operation will eventually be completed, but the operational schedule will be disrupted. In turn, the amount of power consumption of the technological or transport module will depend on the forces of resistance and speed of operations to be performed. The speed of executing the operations will depend on the required productivity. Resistance forces will depend on several factors, and, of course, the type of operations performed. For example, when cultivating stumps - on the composition, moisture, and physical and mechanical properties of the soil, as well as the thickness of the cultivated soil layer, the width of the working surface of 
the site, the quality of execution and maintenance of the working bodies of soil cultivation facilities. When harvesting the grown wood biomass - on the breed, moisture, wood temperature, quality of execution, and service of technological equipment - chainsaws or disk cutter. The results of this work are original and valuable from a practical point of view and can help forest and farm households to assess the effectiveness of the target tree species in terms of soil type. It is also important to evaluate the choice of techniques and technological solutions that can be provided by the modeling considering the technical parameters of the equipment. The works Marinov and Jordanova $[18,19]$ present the results of the study of some logging machines` characteristics with a multi-purpose forest cultivator during the excavation of poplar areas in north-western Bulgaria. As indicated, optimal conditions for high productivity at shredding stumps with a diameter of up to $65 \mathrm{~cm}$, as well as cleaning debris and milling soil depths up to $0.5 \mathrm{~m}$ were established for a tractor PT-400 with a cultivator FAE 300 / S considering technical parameters and fuel consumption. A similar study evaluated the costs and revenues of poplar plantations in Serbia, where trees were cultivated on different types of soils under similar planting conditions [20]. The results also demonstrate differences depending on soil type and socio-economic level in the region. These works are in good agreement with the results of this research, which also indicates the importance of different aspects in the target forest plantation to make this type of economy and environment more attractive.

The sustainability of targeted plantations not only ensures a constant profit but also provides sustainable management of arid and semi-arid forests and areas to create new forests on barren landscapes. According to a study of dry forests in Turkey [21], the increase in agricultural land, fires, and intensive deforestation have resulted in a $26 \%$ reduction of forest area between 1945 and 2014. The practice of target planting and reforestation also demonstrates high economic development and ecological level in the abandoned farms of Brasilia [22], semiarid areas of China [23], Spain [24], etc. Besides, according to Ersson [5], mechanized tree planting is a promising method in terms of economic efficiency through training, planting plan, and technology development. An analysis of the productivity of the Swedish and Finnish forest industries shows that the technical improvement of planting machines increases economic efficiency, even if yields do not increase. It points to the importance and value of developing the scientific and technological potential to generate not only the energy value of the product but also the technologies and techniques for growing.

\section{Conclusions}

Thus, the results of this research allow drawing the following conclusion. The estimation of accumulating the energy value of trunk wood is presented, according to which deciduous trees accumulate more energy reserves by the age of ripeness compared to that of coniferous trees, whose ripeness is much higher. Considering the energy costs required for growing different types of trees, two main types of target energy plantations were established, which differ in the number of seedlings and planting of trees at each rotation. According to the assessment of technical characteristics of machine systems, dimensional characteristics have been developed for single-row and twined rows of cuttings planting schemes and the technological cycle of forest plantation operation. A mathematical model has been established, which allows selecting equipment for the operation on the forest tree plantation to obtain maximum profit at the end of the growing cycle. The principle of modular division of machine's system on power, technologic, and transport modules varying in purpose, optimization criteria of operational parameters and indicators are offered. The findings of this work provide a valuable contribution both from a scientific and experimental point of view. The obtained mathematical model of target planting optimization can be applied in forestry and agricultural complexes. The developed methods can be studied for other types of planting systems used in other countries, which allows for further research in this area.

\section{Acknowledgments}

The work was carried out within the confines of the scientific school "Advances in lumber industry and forestry".

\section{Ethical issue}

Authors are aware of, and comply with, best practice in publication ethics specifically with regard to authorship (avoidance of guest authorship), dual submission, manipulation of figures, competing interests and compliance with policies on research ethics. Authors adhere to publication requirements that submitted work is original and has not been published elsewhere in any language.

\section{Competing interests}

The authors declare that there is no conflict of interest that would prejudice the impartiality of this scientific work.

\section{Authors' contribution}

All authors of this study have a complete contribution for data collection, data analyses and manuscript writing.

\section{References}

1. Galik CS, Murray BC, Mitchell S, Cottle P. Alternative approaches for addressing non-permanence in carbon projects: an application to afforestation and reforestation under the Clean Development Mechanism. Mitigation and adaptation strategies for global change. 2016 Jan 1;21(1):101-18.

2. Zhang Y, Liang S. Changes in forest biomass and linkage to climate and forest disturbances over Northeastern China. Global change biology. 2014 Aug;20(8):2596-606

3. Murray BC, Galik CS, Mitchell S, Cottle P. Alternative Approaches to Addressing the Risk of Non-Permanence in Afforestation and Reforestation Projects under the Clean Development Mechanism. World Bank; 2012 Nov 20.

4. Vagweldi A, Feher,Sh, Khorvat B, Koman S, Kovach G, Sabo L, Tsupi I, Grigoriev IV, Grigorieva OI, Danilov D, Kunitskaya OA, Krivash E. Cultivation and exploitation of forest plantations. University of West Hungary Pres. 2016.

5. Ersson BT, Laine T, Saksa T. Mechanized tree planting in Sweden and Finland: Current state and key factors for future growth Forests. 2018 Jul;9(7):370.

6. Lundmark H, Josefsson T, Östlund L. The introduction of modern forest management and clear-cutting in Sweden: Ridö State Forest 1832-2014. European Journal of Forest Research. 2017 Apr $1 ; 136(2): 269-85$

7. Mola-Yudego B, Arevalo J, Díaz-Yáñez O, Dimitriou I, Haapala A, Ferraz Filho AC, Selkimäki M, Valbuena R. Wood biomass potentials for energy in northern Europe: Forest or plantations? Biomass and Bioenergy. 2017 Nov 1;106:95-103.

8. Larocque GR, DesRochers A, Larchevêque M, Tremblay F, Beaulieu J, Mosseler A, Major JE, Gaussiran S, Thomas BR, Sidders D, Périnet P. Research on hybrid poplars and willow species for fastgrowing tree plantations: Its importance for growth and yield, silviculture, policy-making and commercial applications. The Forestry Chronicle. 2013 Feb;89(1):32-41

9. Laarmann D, Korjus H, Sims A, Kangur A, Kiviste A, Stanturf JA. Evaluation of afforestation development and natural colonization on a reclaimed mine site. Restoration Ecology. 2015 May;23(3):301-9.

10. Dubenok NN, Tanyukevich VV, Tyurin SV. State and reclamation efficiency of forest shelterbelts of Krasnodar krai. Russian Agricultural Sciences. 2017 Mar 1;43(2):170-2. 
11. Krylov A, McCarty JL, Potapov P, Loboda T, Tyukavina A, Turubanova S, Hansen MC. Remote sensing estimates of standreplacement fires in Russia, 2002-2011. Environmental Research Letters. 2014 Oct 10;9(10):105007.

12. Shmulsky R, Jones PD. Forest products and wood science: an introduction. John Wiley \& Sons; 2019 Mar 11.

13. Shackleton CM, Pandey AK. Positioning non-timber forest products on the development agenda. Forest Policy and Economics. 2014 Jan 1;38:1-7.

14. Sheng J, Han X, Zhou H. Spatially varying patterns of afforestation/reforestation and socio-economic factors in China: a geographically weighted regression approach. Journal of Cleaner Production. 2017 Jun 1;153:362-71.

15. Schirmer J, Bull L. Assessing the likelihood of widespread landholder adoption of afforestation and reforestation projects. Global Environmental Change. 2014 Jan 1;24:306-20.

16. Grigorev I, Khitrov E, Kalistratov A, Bozhbov V, Ivanov V. New approach for forest production stocktaking based on energy cost. International Multidisciplinary Scientific GeoConference Surveying Geology and Mining Ecology Management, SGEM. 2014; 14:407-14.

17. Grigoriev IV, Grigoriev MF, Stepanova DI. Perspectives of modular systems of machinery for forest management in Yakutia. Relevant trends of scientific research in XXI century: theory and practice. 2017;9(35):74-77.

18. Marinov K, Jordanova V. Evaluation of forest milling machine performances for site preparation. Innovation in woodworking industry and engineering design. $2015 \mathrm{Feb}$;(8):18-29.

19. Marinov K, Jordanova V. Comparative Analysis of Site Preparation Costs of Poplar Plantations Establishment by Various Technological Schemes. Journal of Agricultural Science and Technology B. 2017;7(2):125-38.

20. Keča L, Pajić S. Costs and revenues in poplar plantations established using full ground and soil preparation in Serbia. InInternational Conference: Reforestation Challenges, Belgrade, Serbia, 36 June 2015. Proceedings 2015 (pp. 234-241). REFORESTA.

21. Çalişkan S, Boydak M. Afforestation of arid and semiarid ecosystems in Turkey. Turkish Journal of Agriculture and Forestry. 2017 Nov 10;41(5):317-30.

22. Knoke T, Bendix J, Pohle P, Hamer U, Hildebrandt P, Roos K, Gerique A, Sandoval ML, Breuer L, Tischer A, Silva B. Afforestation or intense pasturing improve the ecological and economic value of abandoned tropical farmlands. Nature communications. 2014 Nov 26;5(1):1-2

23. Mao R, Zeng DH. Changes in soil particulate organic matter, microbial biomass, and activity following afforestation of marginal agricultural lands in a semi-arid area of Northeast China. Environmental Management. 2010 Jul 1;46(1):110-6.

24. Vadell E, de-Miguel S, Pemán J. Large-scale reforestation and afforestation policy in Spain: A historical review of its underlying ecological, socioeconomic and political dynamics. Land Use Policy. 2016 Sep 1;55:37-48. 